\title{
Foot reflexology in feet impairment of people with type 2 diabetes mellitus: randomized trial ${ }^{1}$
}

\author{
Natália Chantal Magalhães da Silva² \\ Érika de Cássia Lopes Chaves ${ }^{3}$ \\ Emilia Campos de Carvalho ${ }^{4}$ \\ Leonardo César Carvalho ${ }^{3}$ \\ Denise Hollanda lunes ${ }^{3}$
}

Objective: to evaluate the effect of foot reflexology on feet impairment of people with type 2 diabetes mellitus. Method: this is a randomized, controlled and blind clinical trial. The sample was comprised by people with type 2 diabetes mellitus who, after being randomized into Treated group $(n=21)$ and Control group $(n=24)$, received guidelines on foot self-care. To the Treated Group it was also provided 12 sessions of foot reflexology. The scores of impairment indicators related to skin and hair, blood circulation, tissue sensitivity and temperature were measured by means of the instrument for assessing tissue integrity of the feet of people with diabetes mellitus. Chi-square test, Fisher exact test, Mann-Whitney test and regression analyzes were applied to the data, considering a significance level of $5 \%$ ( $P$ value $<0.05$ ). Results: participants who received the therapy showed better scores in some impairment indicators related to skin and hair (hair growth, elasticity/turgor, hydration, perspiration, texture and integrity of the skin/ skin peeling). Conclusion: the foot reflexology had a beneficial effect on feet impairment of people with type 2 diabetes mellitus, which makes it a viable therapy, deserving investment. This study was registered in the Brazilian Registry of Clinical Trials - RBR-8zk8sz.

Descriptors: Nursing; Massage; Diabetes Mellitus, Type 2; Lower Extremity.

\footnotetext{
${ }^{1}$ Paper extracted from master's thesis "Effects of reflexology no commitment of feet of patients with diabetes mellitus: randomized trial", presented to Escola de Enfermagem, Universidade Federal de Alfenas, Alfenas, MG, Brazil. Supported by Conselho Nacional de Desenvolvimento Científico e Tecnológico (CNPq), Brazil, process \# 401126/2013-7.

2 Doctoral student, Escola de Enfermagem de Ribeirão Preto, Universidade de São Paulo, PAHO/WHO Collaborating Centre for Nursing Research Development, Ribeirão Preto, SP, Brazil.

3 PhD, Professor, Escola de Enfermagem, Universidade Federal de Alfenas, Alfenas, MG, Brazil.

${ }^{4}$ PhD, Full Professor, Escola de Enfermagem de Ribeirão Preto, Universidade de São Paulo, PAHO/WHO Collaborating Centre for Nursing Research Development, Ribeirão Preto, SP, Brazil.
}

Corresponding Author:

Natália Chantal Magalhães da Silva

Universidade Federal de Alfenas. Escola de Enfermagem

Rua Gabriel Monteiro da Silva, 700

Centro

CEP: 37130-000, Alfenas, MG, Brasil

E-mail: naty_chantal@hotmail.com
Copyright () 2015 Revista Latino-Americana de Enfermagem This is an Open Access article distributed under the terms of the Creative Commons Attribution Non-Commercial License (CC BY-NC).

This license lets others distribute, remix, tweak, and build upon your work non-commercially, and although their new works must also acknowledge you and be non-commercial, they don't have to license their derivative works on the same terms. 


\section{Introduction}

Among the complications caused by type 2 diabetes mellitus, arteriopathy and peripheral neuropathy configure the main complications of the lower limbs ${ }^{(1-2)}$. These changes along with the decrease of tissue elasticity and reduction in the range of joint motion during step may lead to an increase in the concentration of distribution of body weight in some regions of plantar surface of foot ${ }^{(1)}$.

Accordingly, these three clinical conditions peripheral arteriopathy, peripheral neuropathy and increased foot plantar pressure - together, may result in skin breakdown and development of injuries(3). The plantar changes should, therefore, be target of care by health professionals, either to prevent possible injuries, or to control those already existing ${ }^{(4)}$.

The nurses, as result of their constant interaction with the diseased population, plays a key role at various healthcare levels ${ }^{(5)}$. Besides being responsible for care providing, the nurse operates in the identification and monitoring of people with diabetes, as well as controlling disease complications ${ }^{(4)}$.

During the nursing consultation of the person with type 2 diabetes mellitus, presence of skin changes and hair distribution, circulation changes, decreased sensitivity and temperature of plantar surface of foot, as well as evaluation of previous history of the disease must be investigated ${ }^{(4)}$. At the same time, the nurse needs to implement actions aiming to humanize care and that are effective for improving the condition of feet ${ }^{(5)}$.

In this trend, the complementary and integrative practices emerge as strategies for the promotion, prevention, treatment and recovery of health(5). Among these therapies, foot reflexology stands out as a method that, by means of pressure on specific points in the feet, aims to stimulate the body's balance(6).

In Brazil, the therapy of reflex points became widely known in 1996, when Elizabeth Graham, a South African reflexologist, taught a course on reflexology for nurses and nursing teaching staff(7). From that moment, even though in an incipient way, studies on foot reflexology in nursing started and, although the use of this therapy in healthcare is still recent, the research findings indicate that it could be used to improve assistance( ${ }^{(8)}$.

According to the reflex theory, organs, glands and other parts of the body are linked to specific points in the hands and feet ${ }^{(6)}$. The therapy provision in the hands, besides allowing the self-administration, can be performed in any place and position, since physical and mental comfort are ensured(9). It is argued, however, that this method should be performed preferably on the feet, receiving the designation of foot reflexology ${ }^{(6.8)}$, since in the feet, reflexes are stimulated naturally by staying a long time under the pressure of the body weight and, because this region is better protected, becoming more sensitive to stimuli ${ }^{(8)}$.

The location of the reflex points in the plantar region, in general, reproduces the human anatomy ${ }^{(6)}$. The top of the hallux corresponds to the head region. Along the medial border of the foot it is represented the spine. Similarly, the right foot corresponds to the right side of the body and the left foot to the left side(8).

Because it aims the body's balance, it is believed that the therapy acts by pressure on the corresponding reflex area, stimulating it when it is hypoactive and calming it when it is hyperactive ${ }^{(9-10)}$. Thus, the foot reflexology may have implications in various clinical conditions. It is necessary, however, scientific evidence certifying the use of the method in healthcare(8).

Based on the increasing impairment of the lower limbs and because type 2 diabetes mellitus is considered one of the major epidemics of the 21st century, it is observed the need to seek therapies that may be used in care and improvement of life quality of people with this disease ${ }^{(11)}$. Therefore, the aim of this study was to evaluate the effect of foot reflexology on feet impairment of people with type 2 diabetes mellitus.

\section{Method}

This is a randomized, controlled and blind clinical trial(12). The target population consisted of people diagnosed with type 2 diabetes mellitus, for at least five years, aged 18 years or more, and registered in the System of Registration and Monitoring of Hypertensive Diabetics of two primary healthcare services of a municipality in the southern region of the state of Minas Gerais. As exclusion criteria, it was considered: presence of ulcers in the feet; amputations of the lower limbs; uncontrolled systemic arterial hypertension; thrombosis; deficits in cognitive abilities; and previous treatment using reflexology.

For the calculation of the sample size, a pilot test was conducted with 12 volunteers who met the eligibility criteria. For this, it was used the statistical software GPower® 3.0.10 (Franz Faut, Universität Kiel Germany, 2008), with a power effect of 0.80 and effect size of $0.68(a=0.05)$ and, in this way, it was found that 
it would be necessary the allocation of 26 participants in each group.

Accordingly, an active search was carried out at primary care services that have integrated the study and it was found that 214 people who were enrolled in the System of Registration and Monitoring of Hypertensive Diabetics had a diagnosis of type 2 diabetes mellitus, for at least five years. Of these, 161 had at least one exclusion criterion. Thus, 53 people who met the proposed eligibility criteria and agreed to participate in the study integrate the research. Participants were stratified according to age group (18-40 years old, 4164 years old and 65 years old or more), gender (male and female) and time since the diagnosis of diabetes (from five to 12 years, from 13 to 19 years and 20 years or more); then they were randomized into two groups: Treated and Control.

The Treated Group consisted of 26 participants who received guidelines on foot self-care and 12 sessions of foot reflexology, while the Control Group had 27 participants who received guidelines on selfcare feet. During follow-up, five participants from the Treated Group and three from the Control Group gave up of participating in the research. Consequently, at the end of the study, data from 45 patients were analyzed (Figure 1).

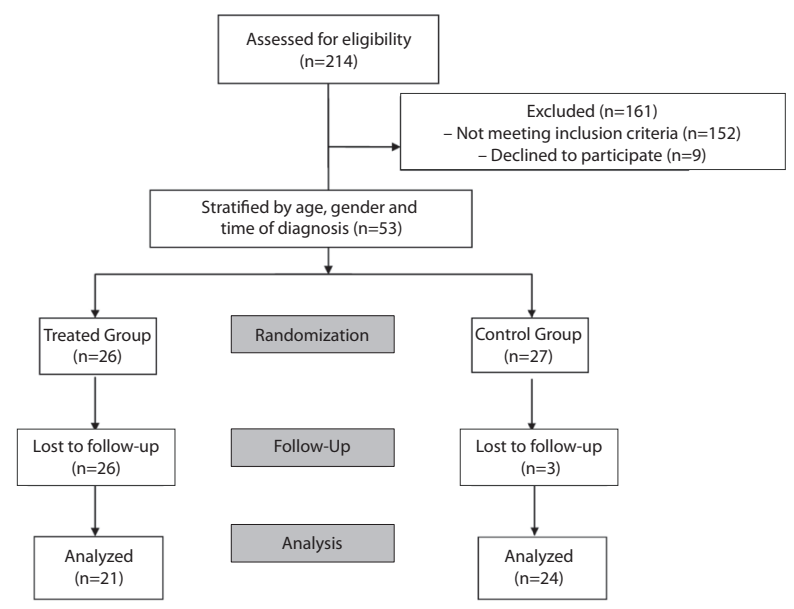

Figure 1 - Flowchart Consort. Alfenas, MG, Brazil, 2014.

To ensure the blinding, the study included an interventionist enabled for application of foot reflexology and a trained evaluator to carry out the analysis of the feet. The evaluator did not know to which group each participant belonged.

There were three analyzes of feet impairment: initial evaluation, before any intervention, 2nd assessment, after the sixth session of foot reflexology, and 3rd evaluation, after the twelfth session. In order to monitor the environment for the procedures standardization, the analysis was performed at a specific place.

For the evaluations, it was applied the instrument for assessing tissue integrity of the feet of people with diabetes mellitus. This instrument allows the analysis isolated of feet impairment from indicators related to skin and hair, blood circulation, tissue sensitivity and temperature and, according to its authors, it was validated by seven expert nurses, showing an excellent concordance level(13). The scores range from " 1 ", which qualifies feet as extremely impaired, to " 5 ", when there is no impairment.

To examine skin and hair, the evaluator paid attention to the presence of tissue damage, hair growth on the skin/hairiness, elasticity/turgor, hydration, perspiration, texture, thickness, color, color after lifting the lower limbs to 30 centimeters height and pigmentation. The blood circulation was evaluated by observing the tissue perfusion, tibial and pedal pulses, and presence of edema and varicose veins. To evaluate the sensitivity, the Diabetic Neuropathy Symptom Score was applied to investigate the presence of neuropathic symptoms, followed by the $10 \mathrm{~g}$ monofilament test, which is considered a suitable survey to assess tactile sensitivity of people with diabetes mellitus ${ }^{(4,14)}$. The tissue temperature of the plantar region was measured using a surface thermometer.

All participants received, after the initial assessment performed at their homes, guidelines on feet self-care, disclosed in the Primary Care Notebook: Diabetes Mellitus ${ }^{(4)}$.

The tested intervention, foot reflexology, was implemented at the homes of participants of the Treated Group, since locomotion to a specific location could cause dropouts. Three therapy sessions a week were performed, totaling 12 sessions over a period of 30 days. These occurred in a systematic way and with previous scheduling, keeping fixed days and hours, in an attempt to reduce possible interference of daily living habits.

The application of foot reflexology followed the assumptions of Eunice Ingham, the first reflexologist to map the feet regarding the points which had effects on the rest of the body ${ }^{(8)}$. According to Ingham, the pressure on reflex points can be applied in any environment, since it offers convenience(6). Accordingly, in this study, it was decided to perform the therapy in the bed of the participants, positioned supine.

There is no sequence to be followed for the application of foot reflexology, but no reflection point can be forgotten, 
since the goal is to balance the entire body by stimulating the areas that correspond to the human body ${ }^{(6)}$. However, in order to maintain uniformity and standardization of the technique, the left foot was massaged first and then the right one and an order of pressure points has been established, first the points located on the toes, then the points located in the lateral and medial portions and, finally, in the plantar surface of feet.

The statistical analysis of the collected data was carried out using the $\mathrm{R}$ software, version 2.15.3(15). For the analysis, it was used the tests: Chi-square test, Fisher exact test, Mann-Whitney test and regression analyzes, considering a significance level of $5 \%$ ( $P$ value $<0.05$ ).

This study is part of a wider project, which was registered in the Brazilian Registry of Clinical Trials (RBR$8 \mathrm{zk} 8 \mathrm{sz}$ ) and has been previously approved by the Ethics Committee (CAAE: 07183512.1.00005142). Before data collection, all participants signed an Informed Consent Form.

\section{Results}

It was found that in the Treated Group, $65 \%$ of participants were female with an average age of 63 years old, average weight of $73.2 \mathrm{~kg}$ and average height of 1.63 meters. In the Control Group, 62\% were women, whose average age was 60 years old, average weight of
$76.6 \mathrm{~kg}$ and average height of 1.62 meters. Regarding these variables and those related to race, marital status, education, occupation, smoking, alcohol consumption, physical activity, presence of other chronic disease or presence of acute disease and type of treatment for diabetes mellitus, significant differences were observed between the groups.

When assessing feet impairment, both indicators related to skin and hair, as well as blood circulation, tissue sensitivity and temperature, it was observed that initially (before any intervention), participants of the Treated Group and Control Group showed similar impairment scores. However, after the implemented interventions, participants who received reflexology exhibited behavior different of the participants in the Control Group, with better scores in some indicators related to skin and hair.

Regarding the hair growth/hairiness, elasticity/ turgor, hydration, perspiration, texture and integrity of the skin/skin peeling, six sessions of foot reflexology were enough to improve significantly the impairment scores of participants who integrated the Treated Group, and this condition was maintained throughout the study. Therefore, it was inferred that in relation to these indicators, the Treated Group showed an increased chance of unchanged results (score " 5 " of impairment) over time, while in the Control Group this result was not observed (Table 1 ).

Table 1 - Comparison of the evaluations between Treated Group and Control Group in the indicators of feet impairment related to skin and hair. Alfenas, MG, Brazil, 2014

\begin{tabular}{|c|c|c|c|c|}
\hline Skin and Hair & Treated Group X Control Group & $\beta^{*}$ & S.E. ${ }^{\dagger}(\beta)$ & P Value \\
\hline \multirow[t]{3}{*}{ Hair growth/Hairiness } & Initial evaluation & 0.86 & 0.58 & 0.133 \\
\hline & 2nd evaluation & -1.66 & 0.61 & $0.007^{\ddagger}$ \\
\hline & 3rd evaluation & -3.15 & 0.84 & $<0.001^{\ddagger}$ \\
\hline \multirow[t]{3}{*}{ Elasticity/Turgor } & Initial evaluation & 1.00 & 0.57 & 0.078 \\
\hline & 2nd evaluation & -1.50 & 0.68 & $0.029 \neq$ \\
\hline & 3rd evaluation & -1.91 & 0.75 & $0.011^{\ddagger}$ \\
\hline \multirow[t]{3}{*}{ Hydration } & Initial evaluation & 0.38 & 0.55 & 0.487 \\
\hline & 2nd evaluation & -1.70 & 0.58 & $0.003^{\ddagger}$ \\
\hline & 3rd evaluation & -2.50 & 0.73 & $0.001^{\ddagger}$ \\
\hline \multirow[t]{3}{*}{ Perspiration } & Initial evaluation & 0.68 & 0.56 & 0.221 \\
\hline & 2nd evaluation & -2.66 & 0.87 & $0.002^{\ddagger}$ \\
\hline & 3rd evaluation & -1.66 & 0.65 & $0.011^{\ddagger}$ \\
\hline \multirow[t]{3}{*}{ Texture } & Initial evaluation & 0.38 & 0.56 & 0.501 \\
\hline & 2nd evaluation & -1.54 & 0.60 & $0.011^{\ddagger}$ \\
\hline & 3rd evaluation & -1.93 & 0.59 & $0.001^{\ddagger}$ \\
\hline \multirow[t]{3}{*}{ Thickness } & Initial evaluation & 0.42 & 0.54 & 0.586 \\
\hline & 2nd evaluation & -0.91 & 0.52 & 0.098 \\
\hline & 3rd evaluation & -0.94 & 0.81 & 0.095 \\
\hline \multirow[t]{3}{*}{ Color } & Initial evaluation & 0.39 & 0.62 & 0.371 \\
\hline & 2nd evaluation & -0.59 & 0.52 & 0.345 \\
\hline & 3rd evaluation & -0.72 & 0.65 & 0.117 \\
\hline
\end{tabular}


Table 1 - (continuation)

\begin{tabular}{|c|c|c|c|c|}
\hline Skin and Hair & Treated Group X Control Group & $\beta^{*}$ & S.E. ${ }^{\dagger}(\beta)$ & P Value \\
\hline \multirow[t]{3}{*}{ Color after 10 seconds lifting the limbs to a $30 \mathrm{~cm}$ height } & Initial evaluation & 0.48 & 0.52 & 0.346 \\
\hline & 2nd evaluation & -0.24 & 0.55 & 0.149 \\
\hline & 3rd evaluation & -0.19 & 0.72 & 0.115 \\
\hline \multirow[t]{3}{*}{ Pigmentation } & Initial evaluation & -1.47 & 1.15 & 0.203 \\
\hline & 2nd evaluation & -0.02 & 1.53 & 0.987 \\
\hline & 3rd evaluation & -0.60 & 1.38 & 0.060 \\
\hline \multirow[t]{3}{*}{ Integrity of the skin/skin peeling } & Initial evaluation & -0.07 & 0.55 & 0.901 \\
\hline & 2nd evaluation & -2.08 & 0.86 & $0.016^{\ddagger}$ \\
\hline & 3rd evaluation & -1.64 & 0.81 & $0.042^{\ddagger}$ \\
\hline
\end{tabular}

*Regression coefficient

+Standard Error

$\neq P$ value $<0.05$

With regard to the indicators of feet impairment related to blood circulation, Treated Group and Control Group remained, in the three assessments, with an average score of " 4 ", slightly impaired, with no significant difference between the groups throughout the study (Table 2).

By verifying the effect of foot reflexology in the indicators related to sensitivity, both Treated Group and Control Group had an average score of " 3 " at the beginning of the research, and feet were qualified with moderate impairment. Although participants showed a score increase throughout the study, there were no significant differences between participants of Treated Group and Control Group (Table 3).

However, in the analysis of tissue temperature, all participants had feet qualified as extremely impaired, with an average score of " 1 ", and with no significant difference between groups (Table 4). During the data collection period, there were no changes, since the groups continued to show the same impairment score for this indicator.

Table 2 - Comparison of the evaluations between Treated Group and Control Group in the indicators of feet impairment related to blood circulation. Alfenas, MG, Brazil, 2014

\begin{tabular}{|c|c|c|c|c|}
\hline Blood Circulation & Treated Group X Control Group & $\beta^{*}$ & S.E. ${ }^{\dagger}(\beta)$ & P Value \\
\hline \multirow[t]{3}{*}{ Tissue perfusion } & Initial evaluation & 0.25 & 0.56 & 0.659 \\
\hline & 2nd evaluation & -1.35 & 0.78 & 0.082 \\
\hline & 3rd evaluation & -0.21 & 0.88 & 0.808 \\
\hline \multirow[t]{3}{*}{ Pedal pulses } & Initial evaluation & 0.94 & 0.61 & 0.122 \\
\hline & 2nd evaluation & -1.05 & 0.93 & 0.256 \\
\hline & 3rd evaluation & -2.21 & 1.34 & 0.099 \\
\hline \multirow[t]{3}{*}{ Tibial pulses } & Initial evaluation & -0.13 & 0.61 & 0.827 \\
\hline & 2nd evaluation & -0.05 & 0.86 & 0.953 \\
\hline & 3rd evaluation & -0.66 & 0.98 & 0.499 \\
\hline \multirow[t]{3}{*}{ Edema } & Initial evaluation & -0.21 & 0.76 & 0.518 \\
\hline & 2nd evaluation & -0.19 & 0.55 & 0.480 \\
\hline & 3rd evaluation & -0.52 & 0.42 & 0.245 \\
\hline \multirow[t]{3}{*}{ Varicose } & Initial evaluation & -0.12 & 0.59 & 0.842 \\
\hline & 2nd evaluation & -0.81 & 0.62 & 0.190 \\
\hline & 3rd evaluation & -0.12 & 0.61 & 0.844 \\
\hline
\end{tabular}

P value $<0.05 ; *$ Regression coefficient; +Standard error.

Table 3 - Comparison of the evaluations between Treated Group and Control Group in the indicators of feet impairment related to sensibility. Alfenas, MG, Brazil, 2014

\begin{tabular}{|c|c|c|c|c|}
\hline Sensibility & Treated Group X Control Group & $\beta^{*}$ & S.E. ${ }^{\dagger}(\beta)$ & P Value \\
\hline \multirow[t]{3}{*}{ Score of neuropathic symptoms } & Initial evaluation & 0.52 & 0.55 & 0.341 \\
\hline & 2nd evaluation & -0.48 & 0.50 & 0.336 \\
\hline & 3rd evaluation & -0.44 & 0.62 & 0.474 \\
\hline \multirow[t]{3}{*}{ 10-g monofilament Test } & Initial evaluation & -0.88 & 0.57 & 0.123 \\
\hline & 2nd evaluation & -0.21 & 0.56 & 0.132 \\
\hline & 3rd evaluation & -0.76 & 0.48 & 0.116 \\
\hline
\end{tabular}

$\mathrm{P}$ value $<0.05 ; *$ Regression coefficient; +Standard error. 
Table 4 - Comparison of the evaluations between Treated Group and Control Group in the indicators of feet impairment related to tissue temperature. Alfenas, MG, Brazil, 2014

\begin{tabular}{|c|c|c|c|c|}
\hline Tissue Temperature & Treated Group X Control Group & $\beta^{*}$ & S.E. ${ }^{\dagger}(\beta)$ & P Value \\
\hline & Initial evaluation & -0.44 & 0.52 & 0.590 \\
\hline & 2nd evaluation & -0.49 & 0.61 & 0.496 \\
\hline & 3rd evaluation & 0.64 & 0.87 & 0.089 \\
\hline
\end{tabular}

P value $<0.05$; *Regression coefficient; +Standard error.

\section{Discussion}

In this study, by evaluating the effects of foot reflexology on feet impairment of people with diabetes mellitus, it was noted that the therapy had no effect in some indicators of feet impairment related to skin and hair, considering a significance level of $5 \%$ ( $P$ value<0.05).

Some researchers state that cutaneous stimulation can contribute for the balance of the body, either at physiological or metabolic level(16-17). Accordingly, by exerting some pressure on the tissue surface, it is possible to trigger systemic reactions ${ }^{(3)}$.

Several studies have shown the effect of the pressure on reflex points in heart rate, blood pressure and reduction of pain and anxiety ${ }^{(18-22)}$. However, no evidence proving the implications of foot reflexology in the feet of healthy people and those with chronic diseases, such as diabetes mellitus, were found in the scientific literature.

It is known that cutaneous stimulation, when exerted in the plantar surface, stimulates limbs vascularization and provides oxygen to the cells responsible for keeping the skin moist, hydrated, with coloring, hairiness, texture and eutrophic thickness ${ }^{(16,23)}$, which explains the effect, in this study, of reflex therapy in some indicators related to skin and hair. Associated to this, it is believed that foot massage contributes to venous return and cooperates with the excretion of toxins present in the blood by stimulating the lymphatic system ${ }^{(23)}$.

However, so that changes occur at certain skin characteristics such as thickness, it is necessary the regeneration of the cells that make up the epidermis ${ }^{(2)}$ and, since this process is controlled by intrinsic and extrinsic factors such as collagen density of the body, exposure to sunlight and daily living habits, generally, it may take days or months ${ }^{(16)}$. Thus, it is clear that 12 sessions of foot reflexology implemented over a period of 30 days were insufficient to produce an effect on skin thickness.

The blood circulation, one of the responsible for pigmentation and temperature of the body surface, depends on a number of factors so that the blood transportation is possible ${ }^{(20)}$. Heart, arteries, arterioles, venules and veins must be anatomically and physiologically preserved so that the perfusion of peripheral tissues occurs effectively ${ }^{(10)}$. In this way, the systemic circulation should be target of evaluation making possible to adjust the duration and the amount of therapy sessions implemented according to the cardiovascular condition ${ }^{(20)}$. In this study, however, there was no evaluation of the cardiac function at a systemic level. Since the person with diabetes is more prone to development of cardiovascular disorders $^{(10)}$, it was found that the number of therapy sessions were insufficient to intervene in the systemic circulation, and thus be effective in the indicators of feet impairment related to color, pigmentation, blood circulation and tissue temperature of feet.

After years of diabetes mellitus finding, peripheral, motor and autonomous nervous system, are commonly affected, either alone or diffusely, causing irreversible neurological changes ${ }^{(17)}$. The majority of participants in this study reported diagnosis of diabetes for 10 years and in such cases, it is believed that there was an increase of peripheral nerve damage ${ }^{(1,3)}$. Therefore, the lack of effects of foot reflexology on the indicator related to sensitivity of the feet is justified by the fact that possibly the participants already had some impairment of sensory innervation of the plantar surface and the therapy could not work repairing this sensitivity, because it is an unrecoverable complication ${ }^{(17)}$.

It is known that thermal regulation is mediated by blood vessels and peripheral nerves, with influence of internal and external factors ${ }^{(17)}$. Hence, the impairment of the blood circulation and sensitivity in the feet of the participants explains the low tissue temperature in Treated Group and Control Group.

In this study, the number of sessions of foot reflexology as well as the absence of daily follow up of factors influencing blood circulation, tissue sensitivity and temperature were considered as a limitation of the research. Thus, it is noteworthy that in order to verify the implications of the intervention on these indicators, conduction of studies providing a larger 
number of sessions of the tested therapy would be necessary. It is also recommended conducting research with a larger sample, which allows the detection of small differences between Treated Group and Control Group.

Based on the results of this study, either as coadjutant to conventional treatment or as first-line therapy, when inserted in nursing care, foot reflexology can contribute to improving the scores of some indicators of feet impairment of people with diabetes mellitus.

In this context, to provide legal support to nurses in the execution of integrative practices, such as reflexology, the Federal Nursing Council supported the Regulatory Opinion number 004/95, which consolidates the integrative therapies as a specialty and/or qualification of nurses(5).

\section{Conclusion}

The study participants who received foot reflexology showed better scores in a few indicators of feet impairment related to skin and hair, when compared to Control Group. In this respect, it was verified improvement in hair growth/hairiness, elasticity/turgor, hydration, perspiration, texture and integrity of the skin/skin peeling. In the other indicators related to skin and hair and those related to blood flow and tissue temperature, however, no significant differences were observed between groups.

Accordingly, in this study, it was observed that reflex therapy showed some beneficial effect, making it a viable practice that deserves investment. Therefore, studies are needed to ensure and certify the application of foot reflexology in feet impairment of people with diabetes mellitus, ensuring their use in nursing care.

\section{References}

1. Chand G, Mishra A, Kumar S, Agarwal A. Diabetic foot. CQN. 2012;1(2):144-50.

2. Bowering K, Embil JM. Foot care. Can J Diabetes. 2013;37 Suppl 5:45-9.

3. Moura LIF, Dias AMA, Carvalho E, Sousa HC. Recent advances on the development of wound dressings for diabetic foot ulcer treatment: a review. [Revisão]. Acta Biomater. 2013;30(1):1-21.

4. Ministério da Saúde (BR). Caderno de Atenção Básica: Diabetes Mellitus. Brasília (DF): Conselho Nacional de Saúde; Ministério da Saúde; 2006. 52 p. Normas e Manuais Técnicos.
5. Nuñes HMF, Ciosak SI. Terapias alternativocomplementares: o saber e o fazer das enfermeiras do distrito administrativo 71 - Santo Amaro - São Paulo. Rev Esc Enferm USP. 2003;37(3):11-8.

6. Ozdemir G, Ovayolu N, Ovayolu O. The effect of reflexology applied on haemodialysis patients with fatigue, pain and cramps. Int J Nurs Pract. 2013;19(1):265-73.

7. Ernst E, Posadzki L. Reflexology: an update of a systematic review of randomized clinical trials. Maturitas. 2011;68(2):116-20.

8. Li CY, Chen SC, Li CY, Gau ML, Huang CM. Randomised controlled trial of the effectiveness of using foot reflexology to improve quality os sleep amongst Taiwanese postpatim women. Midwifery. 2011;27(1):181-6.

9. Wright S, Courtney U, Donnelly C, Kenny T, Lavin C. Clients' perceptions of the benefits of reflexology on their quality of life. Complement Ther Nurs Midwifery. 2002;8(1):69-76.

10. Jones J, Thomson P, Lauder W, Howie K, Leslie S. Reflexology has an acute immediate haemodynamic effect in healthy volunteers: A double-blind randomised controlled trial. Complement Ther Clinl Pract. 2012;30(1):1-8.

11. American Diabetes Association. Standards of Medical Care in Diabetes - 2013. Diabetes Care. 2013; 36 Suppl 1:11-66.

12. Vaz D, Santos L, Machado M, Caneiro, AV. Métodos de Aleatorização em Ensaios Clínicos. Rev Portuguesa Cardiol. 2004;23(5):742-55.

13. Silva NCM, Chaves ECL, Carvalho EC, Iunes DH. Avaliação dos pés de com de diabetes mellitus: uma proposta de escala. Acta Paul Enferm. 2013;26(6):53541.

14. Moreira RO, Castro AP, Papelbaum M, Appolinario JC, Ellinger VCM, Coutinho WF, et al. Tradução para o português e avaliação da confiabilidade de uma escala para diagnóstico da polineuropatia distal diabética. Arq Bras Endocrinol Metabol. 2005;49(6): 944-50.

15. R Development Core Team. R: A language and enviroment for statistical computing [internet]. Vienna (AUT): R foundation for statistical computing [2012]. ISBN 3-900051-07-0. Disponível em: http://www.rproject.org/. Acesso em: 12 jan 2014.

16. Fogaça MC, Carvalho WB, Verreschi ITN. Estimulação tátil-cinestésica: uma integração entre pele e sistema endócrino? Rev Bras Saúde Materno Infantil. 2006;6(3):277-283. 
17. Papanas N, Ziegler D. New diagnostic tests for diabetic distal symmetric polyneuropathy. J Diabetes Complications. 2011;25(1):44-51.

18. Oleson T, FloccoW. Randomized controlled study of premenstrual symptoms treated with ear, hand and foot reflexology. Obstet Gynecol. 1993;82(6):906-11.

19. Arbizu RLT, Reventós KE, Fernendez MTL, Pardeño SAD. Efecto pos-tratamiento de la reflexoterapia podal en la tensión arterial y la frecuencia cardiaca: estudio piloto. Fisioterapia. 2006;28(3):125-32.

20. Sanchez MMC, Lorenzo M, Peñarrocha $M$, Ojeda JA, Labraca NS, Ortega FZ. Diminuición de la presión arterial en pacientes con arteriopatía periférica mediante el masaje reflejo del tejido conjuntivo. Fisioterapia. 2009;31(2):50-4.

21. Valiani M, Babaei E, Heshmat R, Zare Z. Comparing the effects of reflexology methods and Ibuprofen administration on students of Isfahan University of Medical Sciences. Iran J Nurs Midwifery Res. 2010;15(1):371-8.

22. Valiani M, Shiran E, Kianpour M, Hasanpour M. Reviewing the effect of reflexology on the pain and certain features and outcomes of the labor on the primiparous women. Iran J Nurs Midwifery Res. 2010;15(1):302-10. 23. Lidgren L, Lehtipalo S, Winso O, Karlsson M, Wiklund $U$, Brulin C. Touch massage: a pilot study of a complex intervention. Nurs Crit Care. 2013;18(13):1-8. 